\title{
The influence of cognitive and psychomotoric functioning on road traffic safety found on simulation-based research
}

\author{
Ewa Odachowska ${ }^{1,}{ }^{*}$, Monika Ucińska $^{1}$, and Kamila Gąsiorek ${ }^{1}$ \\ ${ }^{1}$ Motor Transport Institute, Transport Telematics Center, Jagiellońska str 80, 03-301 Warsaw
}

\begin{abstract}
Perceptual and attention processes involved in information processing are engaged during every single activity taken by an individual, including driving a vehicle. They are considered to be one of the most important driver characteristics. It is assumed that safe driving consists of quick and accurate spotting and isolating events important for road traffic safety. The other crucial factor is the reduction of the information excess coming to human in one certain moment. Thanks to that, only an important part of stimuli reaching the senses is perceived in a way enabling the use of certain information from memory structures and the launch of further reaction processes.
\end{abstract}

\section{Introduction}

Driver's psychomotoric and cognitive functioning is a significant factor influencing the road traffic safety. In this regard, the road surroundings have to be adapted to the perceptual capabilities of the road users. Literature analyzes and own experience have shown that psychological aspects play an important role in the experimental mark research. This may be the basis for the assessment guidelines development for e.g. road signs comprehensibility and their impact on driver behaviour patterns near the mark.

\section{Objectives}

The aim of the study was to answer whether the perception of the road environment, associated reaction time, temperament as well as attention and spread of memory have a direct impact on the perception of the road environment, road marking and errors made in road traffic. The goal was also to investigate how drivers perceive and analyze the traffic environment, in which places they fixate their sight, in order to behave correctly with road markings. Previous studies on the psychophysical driver features were made using modern measurement technology and brought a number of insights and conclusions possible to implement in road design. Road marking plays an important role from roadworthiness and safety point of view. The signs give the road users some coded information. In order to

\footnotetext{
* Corresponding author: ewa.odachowska@its.waw.pl
} 
receive this information, it is necessary to have an appropriate knowledge enabling correct decoding and making the right decisions based on the transmitted message. The more clearly and unambiguous the labeling is, the faster and more easily the vehicle driver is able to take an appropriate action. On the other hand, it is the elements of the psyche that play a significant role in the proper functioning of the expensive traffic based on the analysis of the road situation and the visible markings. It should also be noted that sometimes, despite good markings, the driver decides to behave improperly. All these elements constitute a feedback and mutually influence each other.

\section{Method}

The research methodology preparation took into the consideration the necessity of analyzing the processes involved in processing the outer information and how they reach the driver. Therefore, the following tools were used in the project: Functional Vision Analyzer (FVA), Vienna Test System (VTS) and so-called paper and pencil interviewing (PAPI). Used tools allowed to thoroughly analyze the parameters of psychomotoric (reaction time) and cognitive functioning (attention, perception and memory) as well as individual predispositions and reaction patterns pictured in the form of temperament variables. During the experiment, the on-road behaviour was investigated, depending on the road choice, signage type etc. Both the performed speed, reaction patterns, eye-tracking tools-based sight fixations as well as other variables influencing the road perception and its surroundings were checked.

The participating examinees were men and women (40.8\%) between 18 and 71 years old $(M=40.08 ; S D=16.15) .29 \%$ of participants had high school education, $11 \%$ had either uncompleted higher education or were studying and $47.4 \%$ had already a university diploma. All participants had a standard driving license (type B in Polish transportation system). However, some of them had also other type of driving licenses (category A $7.9 \%$; category $\mathrm{C}-3.9 \%$; category $\mathrm{D}-2.6 \%$; category $\mathrm{B} \& \mathrm{E}-1.3 \%$; category $\mathrm{C} \& \mathrm{E}-$ $1.3 \%$; category D \& $\mathrm{E}-1.3 \%)$. The driving experience was spread from 1 year to 44 years $(M=15.39 ; S D=13.25)$. The participants in had assessed their driving skills as average $(11.8 \%)$, good $(73.7 \%)$, and very good $(14.5 \%)$. The respondents in the study also claimed that they drive a car: a few times a year $(1.8 \%)$, few times a month $(19.7 \%)$, few times a week $(30.3 \%)$, and every day (48.7\%). $14.5 \%$ of participants drive up to $250 \mathrm{~km}$ within a single month, $52.5 \%$ exceed the distance of $260-859 \mathrm{~km}$ per month, $21.1 \%-860-1700$ $\mathrm{km}$, and $11.8 \%$ above $1800 \mathrm{~km}$ monthly. $30.3 \%$ of them spend an average of hour a day behind the wheel, $57.9 \%$ drive for a 2 - 3 hours daily, $10.5 \%$ - between 4 and 7 hours, and $1.3 \%$ more than 8 hours daily.
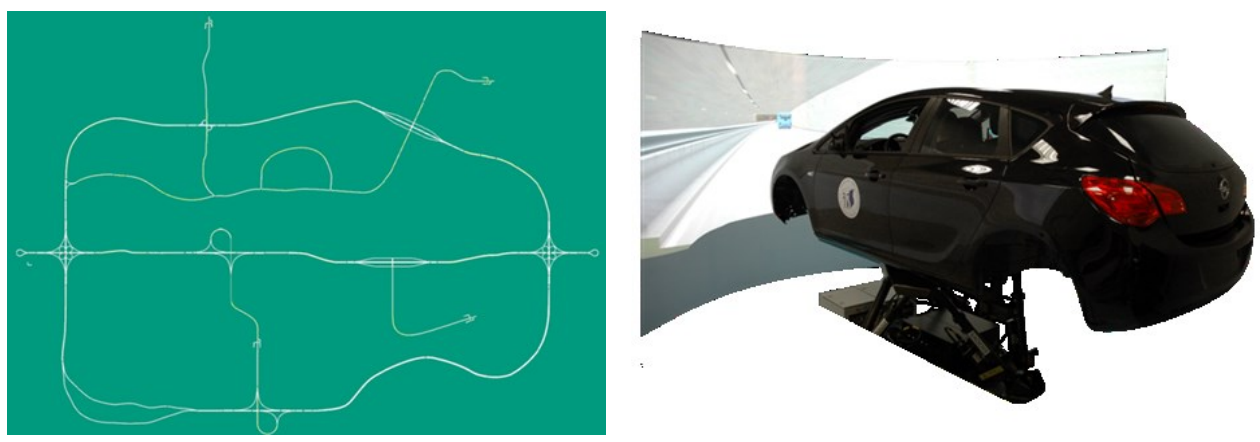

Fig. 1. Example of scenario in simulation environment. 
The following figures present an example of scenario in simulation environment (Figure 1) and experimental marks within scenario 2 of the experiment (Figure 2).

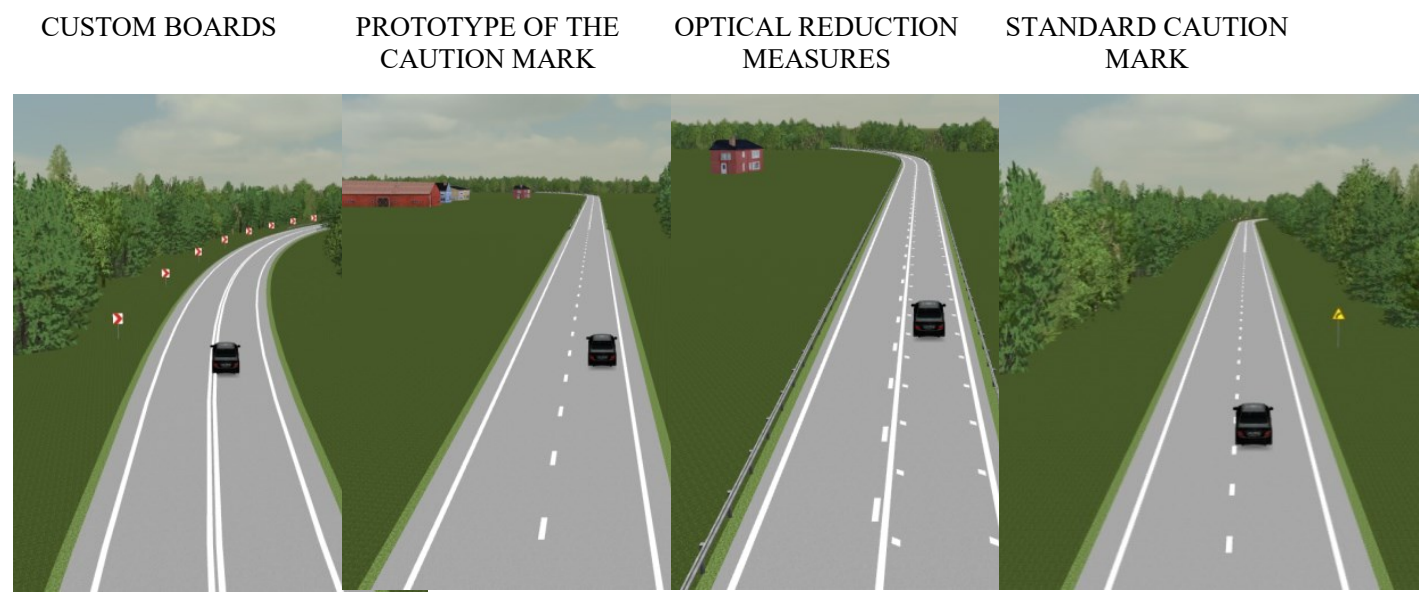

Fig. 2. Experimental marks (EM) at 2 scenario.

The study consisted of two stages. The first stage allowed to check psychological variables using methods described above, while in the second one the driver's behaviour was evaluated in simulation environment in 3 situations. In the first situation (fig. 1), the driver behaviour was analyzed with a standard marking in comparison to the experimental mark (EM) shown in the form of a pictogram and booming lines. In the second situation, the behaviour was checked on 3 different arcs ( 1 to the right Alfa $=380,2$ left to the right Alfa $=38 \mathrm{o}, 3$ to the right Alfa $=49 \mathrm{o}$ ) marked as standard and using 3 variants of EM (fig. 2 ). In the 3 rd one, an eye-tracker was used to check eye fixation on the markings and surroundings.

\section{Results}

The participants' behaviour was analyzed in every situation depending on psychological conditions. The temperamental and cognitive functioning variables, such as attentiveness, stereopsy angle, visual acuity, perception of contrast, peripheral field of view, eye fixation on marks, orientation in road traffic, reaction time and others were checked.

The results showed many significant relationships indicating the necessity to adjust the signage to perceptual capabilities of traffic users. The respondents largely chose the signs clearly indicating the type of behaviour. It was noticed that knowledge of the sign meaning isn't clear regarding the choice of behaviour. In the second case, many affinities were noted regarding behaviour in the context of a given sign depending on psychological conditions.

In the first scenario we analyzed the relationship between psychological variables such as temperamental characteristics, attention and perceptiveness, with drivers' behaviour (speed measurement) at certain road signs depending on the driving mode. The results in form of rho - Spearman's correlation coefficients (non-normality of distribution was taken into consideration) are presented in Table 1. 
Table 1. Correlation matrix with rho-Spearman coefficients for speed and temperamental and attentiveness variables in the first scenario, $\mathrm{N}=76$.

\begin{tabular}{|c|c|c|c|c|c|c|c|c|}
\hline & \multicolumn{6}{|c|}{ Temperament features } & \multicolumn{2}{|c|}{ Attentiveness } \\
\hline & $\begin{array}{l}\text { Brisk- } \\
\text { ness }\end{array}$ & $\begin{array}{l}\text { Perse- } \\
\text { verati- } \\
\text { on }\end{array}$ & $\begin{array}{l}\text { Sensory } \\
\text { Sensiti- } \\
\text { vity }\end{array}$ & $\begin{array}{l}\text { Emo- } \\
\text { tional } \\
\text { Reacti } \\
\text {-vity }\end{array}$ & $\begin{array}{l}\text { Endu- } \\
\text { rance }\end{array}$ & $\begin{array}{l}\text { Acti- } \\
\text { vity }\end{array}$ & SP & LO \\
\hline \multicolumn{9}{|l|}{ Ruffling lines } \\
\hline Free ride & -0.18 & 0.05 & -0.18 & -0.14 & 0.00 & 0.06 & 0.06 & -0.14 \\
\hline $\begin{array}{l}\text { Ride by the } \\
\text { mark }\end{array}$ & -0.08 & 0.12 & -0.20 & 0.03 & -0.04 & 0.14 & 0.14 & -0.10 \\
\hline Start of curve & -0.01 & 0.13 & -0.04 & 0.10 & -0.10 & 0.00 & 0.01 & -0.11 \\
\hline End of curve & -0.21 & 0.02 & $-0.30 *$ & -0.18 & 0.02 & 0.06 & 0.19 & -0.08 \\
\hline $\begin{array}{l}\text { Free ride behind } \\
\text { the curve }\end{array}$ & $-0.25 *$ & 0.02 & $-0.29 *$ & -0.09 & 0.06 & -0.06 & 0.02 & -0.11 \\
\hline \multicolumn{9}{|c|}{ Standard marking } \\
\hline Free ride & $-0.34 * *$ & -0.03 & $\begin{array}{c}- \\
0.44^{* * *}\end{array}$ & -0.16 & -0.12 & -0.01 & -0.02 & -0.06 \\
\hline $\begin{array}{l}\text { Ride by the } \\
\text { mark }\end{array}$ & -0.15 & 0.12 & $-0.23 *$ & 0.02 & -0.04 & -0.08 & 0.06 & -0.06 \\
\hline Start of curve & -0.20 & 0.07 & $-0.24 *$ & 0.03 & -0.12 & -0.04 & 0.02 & -0.04 \\
\hline End of curve & -0.14 & 0.04 & $-0.30 * *$ & -0.06 & -0.07 & 0.02 & 0.03 & -0.11 \\
\hline $\begin{array}{l}\text { Free ride behind } \\
\text { the curve }\end{array}$ & $-0.33 * *$ & -0.07 & $\stackrel{-}{0.40^{* * * *}}$ & -0.16 & -0.04 & -0.03 & -0.02 & -0.10 \\
\hline \multicolumn{9}{|l|}{ Pictograms } \\
\hline Free ride & -0.16 & 0.15 & $-0.23 *$ & -0.05 & -0.09 & -0.04 & 0.10 & -0.09 \\
\hline $\begin{array}{l}\text { Ride by the } \\
\text { mark }\end{array}$ & -0.23 & 0.01 & $-0.34 * *$ & -0.02 & -0.07 & -0.01 & 0.16 & -0.09 \\
\hline Start of curve & -0.03 & $0.24^{*}$ & -0.09 & 0.02 & -0.16 & 0.02 & 0.12 & -0.01 \\
\hline End of curve & -0.11 & 0.10 & $-0.32 * *$ & -0.12 & -0.14 & 0.03 & 0.12 & -0.07 \\
\hline $\begin{array}{l}\text { Free ride behind } \\
\text { the curve }\end{array}$ & $-0.31 * *$ & 0.08 & $-0.38 * *$ & -0.16 & -0.16 & 0.01 & 0.04 & -0.03 \\
\hline
\end{tabular}

${ }^{*} \mathrm{p}<.05, * * \mathrm{p}<.01, * * * \mathrm{p}<.001$

The highest correlations were recorded in the case of Briskness and Sensory Sensitivity. The most evident associations were observed for standard markings which the drivers usually see in natural road situations. Drivers who rode faster on such markers achieved lower scores in the Sensory Sensitivity scale. In general, the direction of associations pointed to lower Briskness and Sensory Sensitivity in relationship to higher speed for particular road signs.

Similar dependencies were analyzed for cognitive and psychomotor psychological variables (Table 2). Also in this case, a wide analysis was made, including the behaviour during a free ride, before and after sign and marking.

Table 2. Correlation matrix with rho-Spearman coefficients for speed and psychological variables in scenario $1, \mathrm{~N}=76$.

\begin{tabular}{|l|l|l|l|l|l|l|}
\hline & $\begin{array}{l}\text { The } \\
\text { overall } \\
\text { result of } \\
\text { the } \\
\text { stereopsy } \\
\text { angle }\end{array}$ & $\begin{array}{l}\text { The } \\
\text { overall } \\
\text { result of } \\
\text { visual } \\
\text { acuity }\end{array}$ & $\begin{array}{l}\text { Perceptio } \\
\text { n of } \\
\text { contrast }\end{array}$ & $\begin{array}{l}\text { Peripheral } \\
\text { field of } \\
\text { view in } \\
\text { degrees }\end{array}$ & $\begin{array}{l}\text { Left field } \\
\text { in degrees }\end{array}$ & $\begin{array}{l}\text { Right } \\
\text { view in } \\
\text { degrees }\end{array}$ \\
\hline Ruffling lines & -0.13 & $\mathbf{0 . 2 4 *}$ & 0.08 & $\mathbf{0 . 2 5 *}$ & 0.16 & $\mathbf{0 . 2 7 *}$ \\
\hline Free ride
\end{tabular}




\begin{tabular}{|c|c|c|c|c|c|c|}
\hline Ride by the mark & -0.08 & $0.26 *$ & -0.07 & $0.40 * *$ & $0.28 *$ & $0.42 * *$ \\
\hline Start of curve & -0.07 & 0.04 & 0.13 & $0.33 * *$ & $0.26^{*}$ & $0.30 *$ \\
\hline End of curve & -0.15 & 0.08 & 0.00 & $0.38 * *$ & $0.32 * *$ & $0.34 * *$ \\
\hline $\begin{array}{l}\text { Free ride behind } \\
\text { the curve }\end{array}$ & -0.11 & 0.16 & 0.03 & 0.22 & 0.12 & $0.26 *$ \\
\hline \multicolumn{7}{|l|}{ Standard marking } \\
\hline Free ride & $-0.24 *$ & $0.35 * *$ & -0.03 & $0.31 * *$ & $0.24 *$ & $0.33 * *$ \\
\hline Ride by the mark & -0.18 & $0.27 *$ & -0.03 & $0.44 * *$ & $0.33 * *$ & $0.47 * *$ \\
\hline Start of curve & $-0.28 *$ & $0.28 *$ & 0.00 & $0.42 * *$ & $0.30 * *$ & $0.47 * *$ \\
\hline End of curve & -0.17 & 0.21 & -0.05 & $0.25 *$ & 0.16 & $0.30 *$ \\
\hline $\begin{array}{l}\text { Free ride behind } \\
\text { the curve }\end{array}$ & -0.14 & 0.22 & 0.04 & $0.27^{*}$ & 0.19 & $0.28 *$ \\
\hline \multicolumn{7}{|l|}{ Pictograms } \\
\hline Free ride & -0.10 & $0.34 * *$ & -0.11 & 0.38** & $0.28 *$ & $0.41 * *$ \\
\hline Ride by the mark & -0.13 & $0.23 *$ & 0.07 & $0.33 * *$ & $0.26 *$ & $0.36 * *$ \\
\hline Start of curve & -0.11 & $0.35 * *$ & -0.05 & $0.44 * *$ & $0.34 * *$ & $0.43 * *$ \\
\hline End of curve & -0.18 & 0.19 & 0.03 & $0.37 * *$ & $0.26 *$ & $0.40 * *$ \\
\hline $\begin{array}{l}\text { Free ride behind } \\
\text { the curve }\end{array}$ & -0.08 & $0.26^{*}$ & -0.03 & $0.40 * *$ & $0.27 *$ & $0.41 * *$ \\
\hline & & & & & & \\
\hline
\end{tabular}

${ }^{*} p<.05,{ }^{* *} p<.01,{ }^{* * *} p<.001$.

According to the presented results, the right view degree value was related to higher speed for all experimental conditions. The better results of left view were also related to higher speed for most of the conditions, besides free ride at the beginning and free ride behind the curve in ruffling lines condition, as well as the curve's end and the free ride behind the curve in standard marking condition. Better peripheral field of view was related to higher speed for every experimental condition except free ride behind the curve. Contrast perception was not related to speed at all. The overall result of visual acuity was only related to speed in some conditions (the better visual acuity, the higher the speed at: free ride and ride by the mark in ruffling lines condition; free ride, ride by the mark, and start of curve in standard marking condition; free ride, ride by the mark, start of curve, and free ride behind the curve in pictograms condition)

The overall result of the stereopsy angle was only related to higher speed in free ride and start of a curve in standard marking condition.

We also checked whether there was a relationship between psychological variables (temperamental and perceptual characteristics) and the choice of alternative road by conducting correlation analysis which results are presented in Table 3 . The choice of alternative road was binary coded ( 1 - the road was chosen).

Table 3. Correlation matrix with $r$ - Pearson's coefficients for speed and psychological variables in scenario $2, \mathrm{~N}=76$.

\begin{tabular}{|l|c|r|r|r|r|r|c|}
\hline $\begin{array}{l}\text { Temperamental and } \\
\text { perceptual variables }\end{array}$ & $\boldsymbol{N}$ & Min & Max & $\boldsymbol{M}$ & $\boldsymbol{S D}$ & $\begin{array}{c}\text { Alterna- } \\
\text { tive road } \\
\text { Z1 }\end{array}$ & $\begin{array}{c}\text { Alterna- } \\
\text { tive road } \\
\text { Z2 }\end{array}$ \\
\hline FCZ-KT. Formal characteristics of behaviour - temperament questionnaire \\
\hline (1) Briskness & 74 & 7 & 18 & 12.27 & 2.32 & -0.01 & -0.06 \\
\hline (2) Perseveration & 74 & 3 & 19 & 10.54 & 3.35 & 0.13 & $\mathbf{0 . 2 9}$ \\
\hline (3) Sensory Sensitivity & 74 & 1 & 19 & 10.28 & 3.76 & 0.18 & 0.23 \\
\hline (4) Emotional Reactivity & 73 & 2 & 18 & 9.26 & 3.36 & 0.19 & $\mathbf{0 . 3 3}^{* *}$ \\
\hline (5) Endurnce & 74 & 4 & 18 & 11.42 & 3.15 & 0.09 & 0.03 \\
\hline (6) Activity & 74 & 7 & 18 & 12.27 & 2.32 & -0.12 & -0.16 \\
\hline TUS - Tests of attention and perceptivity \\
\hline (7) SP - speed of work & 76 & 351 & 1141 & 704.7 & 161.2 & -0.05 & 0.04 \\
\hline
\end{tabular}




\begin{tabular}{|l|c|c|c|c|c|c|c|}
\hline (8) LB - number of errors & 76 & 0 & 10 & 0.17 & 1.16 & $\mathrm{a}$ & $\mathrm{a}$ \\
\hline $\begin{array}{l}\text { (9) LO - number of } \\
\text { ommissions }\end{array}$ & 76 & 0 & 26 & 7.38 & 6.01 & 0.05 & 0.09 \\
\hline
\end{tabular}

$* p<.05, * * p<.01, * * * p<.001$.

The choice of alternative road Z2 coexisted with higher Perseveration and Emotional Reactivity. Additional analysis showed that, the choice of alternative road Z1 was related to the choice of the alternative road $\mathrm{Z} 2, \mathrm{r}(73)=.80, \mathrm{p}<.001$.

In the second scenario, we examined whether the speed at particular angles was related to the type of road sings (non-standard signs, prototype of a sign, optical means of speed reduction, and standard road signs. In order to do so, we performed one-way withinsubjects ANOVA. The results are included in Table 4 and Figure 3.

Table 4. The results of One-way within-subjects ANOVA, $\mathrm{N}=76$.

\begin{tabular}{|c|c|c|c|c|c|c|c|c|}
\hline & \multicolumn{2}{|c|}{ Speed } & \multirow[b]{2}{*}{$S S$} & \multirow[b]{2}{*}{$d f$} & \multirow[b]{2}{*}{$M S$} & \multirow[b]{2}{*}{$F$} & \multirow[b]{2}{*}{$p$} & \multirow[b]{2}{*}{$\eta^{2}$} \\
\hline & $M$ & $S D$ & & & & & & \\
\hline Within-subjects factor ${ }^{\mathrm{a}}$ & & & 877.26 & 2.35 & 373.49 & 33.35 & $<0.001$ & 0.31 \\
\hline Error & & & 1946.76 & 173.81 & 11.20 & & & \\
\hline Custom boards & 80.15 & 14.90 & & & & & & \\
\hline $\begin{array}{l}\text { Prototype of the caution } \\
\text { mark }\end{array}$ & 83.65 & 14.11 & & & & & & \\
\hline $\begin{array}{l}\text { Optical means of speed } \\
\text { reduction }\end{array}$ & 80.74 & 14.76 & & & & & & \\
\hline Standard caution mark & 84.01 & 13.65 & & & & & & \\
\hline
\end{tabular}

a-Greenhouse-Geisser correction was used since the assumption of sphericity was not met

As seen, the speed value significantly differed for experimental conditions. Then, the analysis of pairwise comparison in form of post-hoc test was conducted.

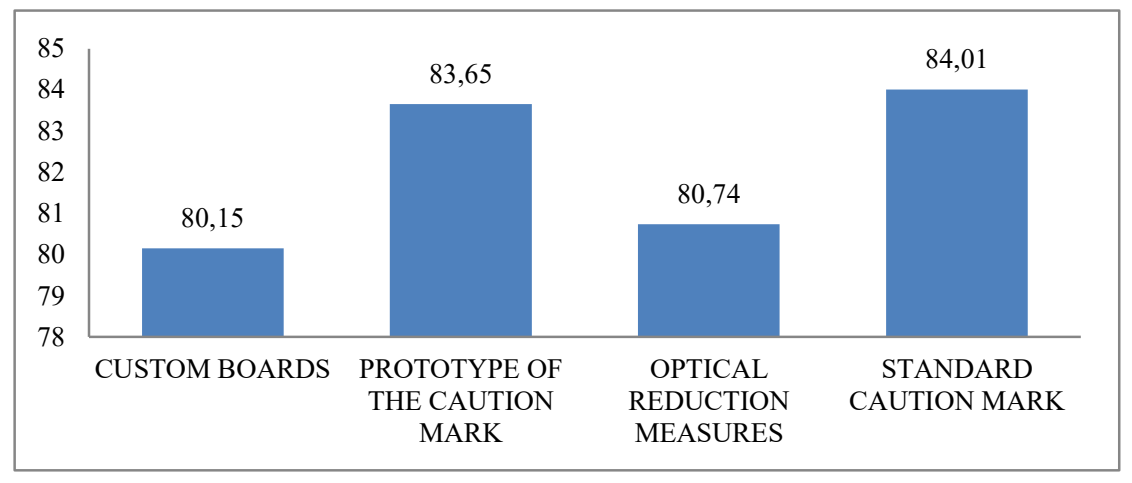

Fig. 3. Comparison of mean velocity in different experimental conditions.

Bonferroni post-hoc test revealed that speed for custom boards scenario was statistically lower in comparison to speed in prototype caution mark scenario $(p<.001)$, as well as in standard caution mark scenario $(\mathrm{p}<.001)$. Additionally, the speed in optical reduction means scenario was lower in comparison to the prototype of the caution mark scenario $(\mathrm{p}<.001)$ and the standard caution mark scenario $(\mathrm{p}<.001)$. The speed level in custom boards scenario in comparison to speed in optical reduction means scenario did not differ significantly.

In the third scenario we analyzed the eye fixation intensity at the particular elements of road signs in relation to the psychological characteristics. The results of correlational analysis are presented in Table 5. 
Table 5. Correlation matrix with rho - Spearman's coefficients for eye fixation at road signs and psychological variables by the type of experimental mark, $\mathrm{N}=76$.

\begin{tabular}{|c|c|c|c|c|c|c|c|}
\hline $\begin{array}{l}\text { Variable } \\
\text { analyzed }\end{array}$ & $\begin{array}{l}\text { Experi- } \\
\text { mental } \\
\text { mark }\end{array}$ & $\begin{array}{l}\text { Brisk- } \\
\text { ness }\end{array}$ & $\begin{array}{l}\text { Perse- } \\
\text { veration }\end{array}$ & $\begin{array}{l}\text { Sensory } \\
\text { Sensiti- } \\
\text { vity }\end{array}$ & $\begin{array}{l}\text { Emotio- } \\
\text { nal } \\
\text { Reacti- } \\
\text { vity }\end{array}$ & $\begin{array}{l}\text { Endu- } \\
\text { rance }\end{array}$ & Activity \\
\hline \multirow{5}{*}{$\begin{array}{l}\text { Average time } \\
\text { of eye fixation } \\
\text { on the } \\
\text { experimental } \\
\text { mark }\end{array}$} & 1 & -0.23 & -0.18 & $-0.26 *$ & 0.04 & 0.03 & 0.09 \\
\hline & 2 & -0.04 & -0.05 & -0.19 & 0.00 & -0.01 & 0.19 \\
\hline & 3 & -0.06 & 0.02 & -0.06 & 0.02 & 0.06 & $0.26 *$ \\
\hline & 4 & -0.11 & 0.02 & $-0.28 *$ & 0.08 & $-0.25 *$ & -0.10 \\
\hline & 5 & 0.03 & 0.12 & 0.00 & 0.13 & 0.09 & 0.14 \\
\hline
\end{tabular}

${ }^{*} p<0,05 ; * * p<0,01 ; * * p<0,001$.

As seen above, longer eye fixation was related to lower sensory sensitivity, but only regarding the experimental mark no 1 . Longer eye fixation was also related to higher activity for the experimental mark no 3. Additionally, the longer fixation accompanied lower sensory sensitivity and endurance in experimental mark no 4 scenario.

\section{Conclusion}

In each scenario it was noted that some psychological variables are important. Regarding the temperament, these were: sensory sensitivity, and regarding the cognitive functions: visual acuity, stereopsy angle and peripheral field of view. This means that these variables should be taken into account when designing the road infrastructure (road environment).

Due to a huge number of variables, a small amount of analyzes is presented here. The results enable to show a number of dependencies between the psychological variables and peripheral environment perception. Thus, they present the behaviour by the vehicle speed driven at the road signs. The most important relationships were observed in the situation of perceptual variables related to sight, memory and perceptiveness. Interesting results were also noted in the context of temperament. Relatively small dependencies were revealed in reaction time.

Correlation matrices with r-Pearson coefficients for speed and psychological variables showed the greatest dependence on stereoscopic and peripheral vision as well as the attention and perceptiveness with the velocities obtained during marking. It was also noted that there is a relationship of two temperament traits (briskness and sensory sensitivity) with the behaviour in the context of characters. It was also found that these variables are important in the case of affixing the eye to individual elements of the road environment and marking.

\section{Summary}

While driving, most of the processes are regulated by attention processes. The driver is unable to be equally focused for a long time due to the existence of alternating and fast neuronal rhythms. Declines of attention and a sudden deconcentration (including the resulting mistakes made at the wheel) the unit is not able to predict completely. These involve e.g. the psychoenergetic processes, i.e. circadian rhythms (diurnal fluctuations of attention) and changes in activation and individual patterns mobilization of action [1]. The driver's attention is constantly stimulated by the external information. Excess messages, number of characters and information about them can cause an information overload to the driver, i.e. some kind of psychological discomfort. It is associated with an attitude to 
receive information, permanent concentration and readiness to receive it [2]. As experiments show, any external interference distracting and causing the driver's vision to turn away from the road for more than two seconds significantly increases the likelihood of an accident [3]. Inadequate road mark form and content may cause driver distraction. This may eventually lead to e.g. unexpected drivers being released within the board or even to a collision or accident. It is therefore important that road marking is clear, unambiguous and as simple as possible. This will allow the driver to respond relatively quickly and adequately.

Discussed results reveal how many factors are engaged in both information spotting and processing. Raised psychological aspects provide the ground for creating the research methodology on the experimental signage's influence on driver behaviour and safety. They should also help in improving the work carried out in implementing new solutions in this area. One of the practical effects of the conducted analyzes may be the appropriate adaptation of road signs labeling to the perceptual and psychomotor abilities, in order to increase the safety of traffic users.

The work was conducted under the Road Innovations Development program (RID) organized and funded by the National Centre for Research and Development and the General Directorate for National Roads and Motorways (contract No. DZP/RID-I-36/5/NCBR/2016).

\section{References}

1. S. Wieczorek, Knowledge in the field of psychological and physiological human capabilities as the basis for predicting errors., Sci. Notebooks Rzesz. Univ. Technol. Manag. Mark. 1234-3706. pp. 147-157 (2004)

2. W. Babik, On the volume of information and related information overload. HumanMedia-Education, Morbitzer J. (ed.) (Cracow, 2010)

3. S.G. Klauer, S.G. Klauer, T. a. Dingus, T. a. Dingus, V.L. Neale, V.L. Neale, J.D. Sudweeks, J.D. Sudweeks, D.J. Ramsey, D.J. Ramsey, The Impact of Driver Inattention on Near-Crash/Crash Risk: An Analysis using the 100-car Naturalistic Driving Study Data. Administration Report No. DOT HS 810594 (National Highway Traffic Safety, Washington, D.C., 2006)

4. E. Nęcka, J. Orzechowski, B. Szymura, Cognitive psychology (Polish Scientific Publishers PWN, Warsaw, 2013)

5. X. Yan, J. Wu, Effectiveness of variable message signs on driving behavior based on a driving simulation experiment, Discret. Dyn. Nat. Soc. 2014 (2014). doi: $10.1155 / 2014 / 206805$ 